\title{
Effect of Pelvic Floor Exercises on Post-Prostatectomy Urinary Incontinence: A Systematic Review
}

\author{
SAMAH HOSNY, Ph.D.; MARWA ABD-ELMOTELB, Ph.D.; HODA ABO-TALEB, Ph.D. and \\ HOSAM EL-DEEN GAMAL, M.Sc. \\ The Department of Physical Therapy for Surgery, Faculty of Physical Therapy, Cairo University and \\ The Department of Applied Statistics and Econometrics, Institute of Statistical and Search, Giza, Egypt
}

\begin{abstract}
Background: Urinary incontinence is a common and costly complication after radical prostatectomy often adversely affecting the quality of life.

Aim of Study: The aim of this systematic review was to examine the effectiveness of pelvic floor exercises on quality of life in post-prostatectomy patients.

Material and Methods: Systematic review of randomized controlled trials, data bases searched were made in PubMed, Pedro, Google scholar and Cochrane, all studies were post 1980 to 2015. Limits were English language.

Intervention: Four relevant randomized controlled trials included the exercise and its effects on quality of life in patients with urinary continence.

Results: Four studies were selected, included in metaanalysis for the primary outcomes as quality of life and secondary outcomes as depression.

Conclusions: There was strong evidence supporting that pelvic floor exercises decrease the frequency of urine leakage. Exercise can be an effective strategy to improve quality of life in patients having post-prostatectomy urinary incontinence.
\end{abstract}

Key Words: Pelvic floor exercises - Prostatectomy - Urinary incontinence.

\section{Introduction}

EVIDENCE-BASED practice is viewed as a mix of (a) Learning what treatments "work" based on the best available research (whether experimental or not), (b) Discussing client views about the treatment to consider cultural and other differences, and to honor client self determination and autonomy, (c) Considering the professionals "clinical wisdom" based on work with similar and dissimilar case that may provide context for understanding

Correspondence to: Dr. Samah Hosny, The Department of Physical Therapy for Surgery, Faculty of Physical Therapy and The Department of Applied Statistics and Econometrics, Institute of Statistical and Search, Giza, Egypt the research evidence, and (d) Considering what the professional can and can not, provide fully and ethically $[\mathbf{1 , 2}]$.

Systematic review is a "study of studies". All relevant research is analyzed in an effort to determine the overall evidence for an intervention. Systematic reviews are generated to answer specific, often narrow, clinical questions in depth [3]

Randomized Controlled Trial (RCT) is considered the gold stander of clinical research. It is the method of choice to compare and study therapeutic interventions and diagnostic tests. It generates the highest level of evidence especially in questions related to intervention and assessment [4].

Urinary Incontinence (UI) is a common and costly complication in men after radical prostatectomy, often adversely affecting their quality of life [5].

Pelvic Floor Muscle Training (PFMT) is a firstline treatment used to restore pelvic floor or bladder function after RP. Pelvic Floor Muscle Training (PFMT) trains subjects to isolate and correctly contract Pelvic Floor Muscles (PFMs) to increase strength and endurance. Repeated contractions are thought to improve urinary control through increased support for the detrusor muscle and the urethral sphincter [6].

Biofeedback can be used as a learning tool to assist subjects on how to contract the PFMs, using visual or auditory feedback through the use of electrical external or internal devices, or verbal feedback from a therapist when a contraction is noted during a digital rectal examination. 
Prostate cancer accounts for approximately one third of cancer in men. Based on excellent survival rate, radical prostatectomy is considered the standard treatment for the management of localized prostate cancer [7]

The effectiveness of different exercise programs after prostatectomy was studied by many researchers as [8]. The evidence base guiding postprostatectomy physiotherapy rehabilitation is somewhat fragmented [9].

Systematic review provides evidence for health care practitioners, patients and health policy makers to make decisions [10].

Therefore we systematically reviewed randomized controlled trials to determine the effectiveness the pelvic floor exercises after prostatectomy in terms of urine leakage, muscle strength, functional activities and quality of life.

\section{Material and Methods}

The following items concerning the methodology of the systematic review were explained:

I- Search strategy.

II- Study selection.

III- Data extraction.

IV- Assessment methodological quality.

V- Data Analysis (synthesis).

Search of published studies was performed in the electronic database register from 1980 to 2015 systematically review published randomized controlled trials in English language which study the exercises therapy and quality of life in postprostatectomy urinary incontinence patients.

Search strategy for identification of studies:

Electronic searches:

- Pub Med (Medline): http://www.ncbi.nlm.nih.gov/ pubmed/and Ovid http://www.ovid.com/site/ index.isp.

- Physiotherapy Evidence Database (Pedro): http:// . www.pedro.org.a

- Google scholar website: http://scholar.google. com.eg/

- Cochrane Central Register of Controlled Trials: http://www.thecochranelibrary.com/view/ 0/index.html.

\section{Other sources:}

Search was performed through the library catalogue Faculty of Physical Therapy, Cairo University.

\section{Search strategy for identification of studies:}

The following key words will be used in the search ,"pelvic floor exercises", "pelvic floor muscle training", "urinary incontinence" and "prostatectomy".

\section{Study selection criteria:}

A comprehensive systematic literature search conducted to identify all relevant articles. The titles and abstracts were initially screened against the inclusion and exclusion criteria for identification of the relevant trials. When the title and abstract weren't clear, the complete article would be read to determine its suitability.

Types of studies:

Published English studies with full text articles of Randomized Controlled Trials (RCTs). Studies published from (1980-2015) were considered.

\section{Participants:}

The review included patients with urinary incontinence after prostatectomy surgeries aged from 60 to 80 years. Patients in the included studies were randomly distributed. The control group didn't participate in any exercise program and the exercise group participated in different types of exercise such as aerobic and resistive exercises.

\section{Interventions:}

This review included randomized controlled trials studies which demonstrate the effect of pelvic floor exercises on quality of lifein patients suffering from urinary incontinence after prostatectomy with reported findings for analysis of its effectiveness.

\section{Outcome measures:}

Systematic review of pelvic floor exercises on quality of life in patients suffering from urinary incontinence after prostatectomy.

\section{Primary outcome:}

- Quality of life.

Exclusion criteria:

- Unpublished studies.

- Study design other than randomized controlled trial (e.g case report, clinical controlled trial cohort study).

- Studies that measured outcomes not related to the scope of our study.

- Not related articles.

- Studies published in language other than English. 


\section{Data collection:}

\section{Study selection:}

After employing the search strategy described above all the studies meeting the inclusion criteria were identified and full text-reports of all relevant trials were obtained and assessed. Excluded studies and reasons for exclusion were stated.

\section{Data extraction:}

Data from all the included studies will be summarized in the following format that includes: participants characteristics (number in each group, target population, diagnosis, numbers in each diagnostic subgroup, and ages), intervention used, research design and level of evidence for the study, and outcomes of interest. Data were extracted directly from the original articles.

\section{Quality assessment of methodology:}

Methodological quality for selected studies was assessed independently by two review authors using Physiotherapy Evidence Database (Pedro) scale. It was more specific scale used to measure the quality of RCTs related to physical therapy interventions, so it was also used to assess quality of studies included in this review. The PEDro scale consists of 11 criteria.

Papers that had a PEDro score of seven or higher, would be considered "high quality", those with a PEDro score of five or six would be considered 'moderate qualty' and those with a PEDro score of four or less would be considered 'poor quality'. The more the number of scores of the aspects evaluating the quality of the study, the more quality of the study [11].

Data analysis: (It may be meta analysis or descriptive analysis).

After extracting data from each study included in this systematic review data were compared and the findings were represented either quantitatively, qualitatively or both according to the homogeneity between studies.

Meta analysis is a quantitative method employing statistical technique to combine and summarize the results of studies that address the same question without major differences in its inclusion or exclusion criteria of the participants, mode of administration, doses, and duration of the intervention as well as the comparison intervention, and the outcomes assessed and the methods of their assessment. Studies should be clinically methodologically and statistically homogenous before combining its results. Confidence Interval (CI) is defined as "the range of scores within which the true score for a variable is estimated to lie within a specified probability (e.g. 90 percent, 95 percent, 99 percent) [12] .

\section{Results}

\section{Literature search results:}

Only four studies met the inclusion criteria (4 randomized controlled trials).

Methodological quality results: The scoring of each study with the Physiotherapy Evidence Database (PEDro) scale. The scores of all studies included in the study ranges from five to eight. The more the number of scores of the aspects evaluating the quality of the study, the more the quality of the study.

The study conducted by (Daniele et al., 2001) examined the results of pelvic floor exercises (PFME) on micturition parameters, urinary incontinence, post-micturition dribbling and quality of life in patients after transurethral prostatectomy (TURP). Fifty-eight consecutive patients who were selected to undergo TURP for Benign Prostatic Hyperplasia $(\mathrm{BPH})$ were admitted into the study: 28 were randomly assigned to a control Group (A) 30 formed the investigational Group (B) during an initial visit conducted before surgery. In Group B patients, perineal exercises were demonstrated in details, and tested for their correct use via simultaneous rectal and abdominal examination.

After the removal of the urethral catheter, these patients were instructed to perform the pelvic floor muscle exercises at home and were evaluated before the exercises and at weekly intervals postoperatively.

The effect of early pelvic floor muscle training that had undergone radical retropubic prostatectomy investigated in the study by (Filocamo, 2005). 300 consecutive patients who had undergone RRP for clinically confined prostate cancer were randomized in two groups after catheter removal. One group of 150 patients took part in a structured PFMT program. This began before discharge and consisted of kegal exercises.

The remaining 150 patients constituted the control group, they were not formally instructed in PFMT. Incontinence was assessed objectively using the 1 hour and 24 hour pad test, as well as with the ICS-Male questionnaire.

The randomized controlled trial conducted by (Manassero et al., 2007) to assess the effect of 
early, intensive and Prolonged Pelvic Floor Muscle exercises (PFME) on urinary incontinence following Bladder Neck (BN) sparing RRP. A sample of 152 patients with localized prostate cancer underwent RRP with BN preservation. Out of this group we randomized 107 incontinent patients in 2 groups. We considered incontinent patients with $24 \mathrm{hr}$ pad test $>2 \mathrm{~g}$. The $\mathrm{T}$ group received instructions regarding an intensive program of PFME, from 7 days after catheter removal as long as degree of incontinent persisted within period of 1 year. The control (C) group did not receive instructions. The outcome was assessed using the $24 \mathrm{hr}$ pad test, a Visual Analogue Scale (VAS) and a single question of QoL. Results at baseline and at 1, 3, 6 and 12 months were available for 54 and 40 patients, respectively.

The study conducted by (Lin et al., 2011) to examine the efficacy of pelvic floor exercises after radical prostatectomy. All participants were older than 45 years and had undergone RP.

After catheter removal, participants were distributed into either an exercise group $(n=39)$ or a non exercise group $(\mathrm{n}=28)$.
Table (1): Methodology assessment of the four studies which met the inclusion criteria and scoring results according to the Physiotherapy Evidence Database (PEDro) scale.

\begin{tabular}{|c|c|c|c|c|}
\hline Criteria & $\begin{array}{l}\text { Daniele } \\
\text { et al., } \\
(2001)\end{array}$ & $\begin{array}{l}\text { Filocamo } \\
\text { et al., } \\
(2005)\end{array}$ & $\begin{array}{l}\text { Manassero } \\
\text { et al., } \\
(2007)\end{array}$ & $\begin{array}{l}\text { Lin } \\
\text { et al., } \\
(2011)\end{array}$ \\
\hline $\begin{array}{l}\text { 1- Specified eligibility } \\
\text { criteria }\end{array}$ & Yes & Yes & Yes & Yes \\
\hline $\begin{array}{l}\text { 2- Random allocation of } \\
\text { participants }\end{array}$ & Yes & Yes & Yes & Yes \\
\hline 3- Concealed allocation & No & No & No & No \\
\hline $\begin{array}{l}\text { 4- similar prognosis at } \\
\text { baseline }\end{array}$ & Yes & Yes & Yes & Yes \\
\hline 5- Blinded participants & No & No & No & No \\
\hline 6- Blinded therapists & No & No & No & No \\
\hline 7- Blinded assessors & No & No & No & No \\
\hline $\begin{array}{l}\text { 8- More than } 85 \% \text { follow-up } \\
\text { for at least one key } \\
\text { outcome }\end{array}$ & Yes & Yes & Yes & Yes \\
\hline 9- Intention to treat analysis & Yes & Yes & Yes & Yes \\
\hline $\begin{array}{l}\text { 10- Between groups statisti- } \\
\text { cal analysis for at least } \\
\text { one key outcome }\end{array}$ & Yes & Yes & Yes & Yes \\
\hline $\begin{array}{l}\text { 11- Point estimates of varia- } \\
\text { bility for at least one key } \\
\text { outcome }\end{array}$ & Yes & Yes & Yes & Yes \\
\hline EDro score & $6 / 10$ & $6 / 10$ & $6 / 10$ & $6 / 10$ \\
\hline
\end{tabular}

Table (2): Summarizes the outcomes of interest of the selected four studies and codes the outcomes of interest.

\begin{tabular}{|c|c|c|c|c|}
\hline Item & Daniele et al., (2001) & Filocamo et al., (2005) & Manassero et al., (2007) & Lin et al., (2011) \\
\hline Research design & Randomized controlled trial & Randomized controlled trial & Randomized controlled trial & Randomized controlled trial \\
\hline Level of evidence & II & II & II & II \\
\hline Participant characteristics & $\begin{array}{l}\text { Patients undergo } \\
\text { transurethral radical } \\
\text { prostatectomy for benign } \\
\text { prostatic hyperplasia }\end{array}$ & $\begin{array}{l}\text { Patients undergo radical } \\
\text { retropubic prostatectomy } \\
\text { and having urinary } \\
\text { incontinence }\end{array}$ & $\begin{array}{l}\text { Patients undergo bladder } \\
\text { neck sparing RRP and } \\
\text { having urinary incontinence }\end{array}$ & $\begin{array}{l}\text { Patients suffer from urinary } \\
\text { incontinence after radical } \\
\text { prostatectomy }\end{array}$ \\
\hline Number of participants: & & & 54 & 39 \\
\hline Treatment group & 30 & 150 & 53 & 28 \\
\hline Control group & 28 & 150 & From 60:70 & Over 45 years \\
\hline Age range & Over 80 years & From $60: 70$ & & \\
\hline
\end{tabular}

Table (3): Summary of study results.

\begin{tabular}{|c|c|c|c|c|}
\hline & Daniele et al., (2011) & Filocamo et al., (2005) & Manassero et al., (2007) & Lin et al., (2011) \\
\hline Intervention & $\begin{array}{l}\text { - Pelvic floor muscle } \\
\text { exercises, perineal exercises } \\
\text { for } 4 \text { weeks }\end{array}$ & $\begin{array}{l}\text { - Pelvic floor training, kegal } \\
\text { exercises for } 6 \text { months }\end{array}$ & $\begin{array}{l}\text { - Intensive prolonged pelvic } \\
\text { floor exercises for } 12 \\
\text { months }\end{array}$ & $\begin{array}{l}\text { - Pelvic floor exercises for } 12 \\
\text { months }\end{array}$ \\
\hline Control intervention & - Placebo is taken & - No PFMT is instructed & - Medication & - Medication \\
\hline Outcome of interest & $\begin{array}{l}\text { - Reduces urinary } \\
\text { incontinence and post- } \\
\text { micturition dribbling }\end{array}$ & $\begin{array}{l}\text { - Reduce voiding and return } \\
\text { to normal life }\end{array}$ & $\begin{array}{l}\text { - Recovery of urinary } \\
\text { incontinence }\end{array}$ & - Reduces urine voiding \\
\hline Measures & - ANOVA-student's $t$-test & - ICS-male questionnaire & - VAS-QoL Pad test & - ANOVA-Pad test \\
\hline Results & $\begin{array}{l}\text { - Improve voiding and quality } \\
\text { of life }\end{array}$ & $\begin{array}{l}\text { - Significantly reduces } \\
\text { incontinence recovery time }\end{array}$ & $\begin{array}{l}\text { - Return to normal life and } \\
\text { improve voiding }\end{array}$ & $\begin{array}{l}\text { - Improve quality of life and } \\
\text { recovery of urinary incontinence }\end{array}$ \\
\hline
\end{tabular}


META analysis:

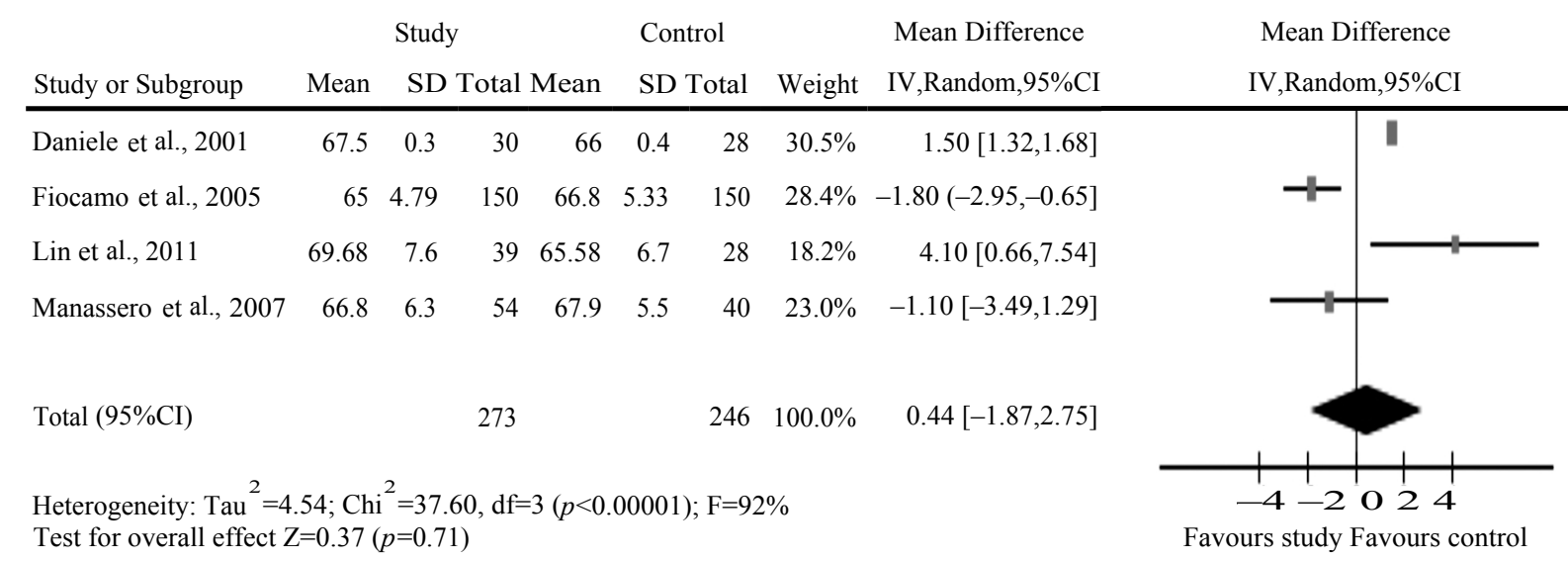

\section{Discussion}

The purpose of current review was to evaluate the effectiveness of pelvic floor exercises on postprostatectomy urinary incontinence. This review include studies from 2001 to 2011 and searched on Medline data base through PubMed and Ovid that most likely include huge amount of papers published every year and also PEDro (a free database of over 18000 RCTs, SRs and clinical practice guidelines in physiotherapy), they search also include Cochrane library and Google scholar web sites.

This SR analyzed four RCTs by applying strict selection criteria for inclusion only full text articles of RCTs were included. All trials met at least six criteria on the PEDro scale.

All collecting data according to items of AACPDM sheet it was found that.

From all four studies included, all studies fulfill the criteria of high methodological quality which judged as strong ("yes" on 6-8 questions) according to PEDro scale.

There was any report about any adverse effects of pelvic floor exercises in the included studies as it is a very safe intervention (100\%) and all the outcomes of the studies represented the ICF component of activity and participation.

The study of Filocamo et al., (2005) determined the effect of early pelvic floor exercises for postprostatectomy urinary incontinence for patients who had undergone radical retropubic prostatectomy and the result demonstrates that after 1 month continence was achieved by 29 patients $(19.3 \%)$ of Group A as opposed to 12 patients $(8 \%)$ of Group B. After 3 months, the numbers were in- creased to 111 patients (74\%) of Group A and 45 patients (30\%) of Group B, whereas after 6 months, the numbers were 144 (96\%) and $97(64.4 \%)$ respectively.

In Group A, patient age correlated significantly with continence 3 to 6 months after surgery, whereas there was no correlation at any time in Group B.

Efficacy of Pelvic Floor Muscle Training (PFMT) is dependant on the intensity of training program, this is based on frequent exercising and also interaction with a health care professional.

This benefit was significant after 3 months when $74 \%$ the treated group regained continence while only $30 \%$ of the control group did. Differences between the two groups in incontinence remained high for the first 6 months and then, it decreased. In fact, at 12 months there was no statistically significant difference between the two groups.

According to the study of Daniele et al., (2001), our study focused on the results of pelvic floor muscle re-education on urinary symptoms and the quality of life after TURP. It is important that patients learn to perform PME appropriately; the first step is to establish awareness of function of the muscles, then regular exercise is encouraged to improve muscle coordination and strength. Muscle contraction strength increased after 4 weeks in the investigational group.

Terminal and post-micturition dribbling are common symptoms after TURP.

They involve the loss of relatively small amounts of urine after each void, causing urinary incontinence. Isolated stress incontinence is rela- 
tively rare after TURP. One patient in Group B had mild urinary incontinence and three in Group A 4 weeks after TURP. Urinary incontinence after TURP or prostatectomy is usual temporary, however, PME can reduce distress.

In the study of Manassero et al., (2007), the difference between the two groups in incontinent patients was $14.2 \%$ after the first month and it progressively increased to $35.9 \%$ at the 12 months, reaching a statistically significant difference. A possible explanation might be that increasing the immediate continence rate selects the most difficult incontinent patients where the physiotherapy needs more time to be successful and we achieved the best results after the 12 months.

Although the degree of initial incontinence was always slightly higher in the T Group, the reduction in terms of the $24 \mathrm{hr}$ pad test shows the significant improvement given by PFE. In both groups, older age significantly increases the possibility to be incontinent and this fact could not be related to worse learning in elderly people, but to their reduced tissue tone.

The $24 \mathrm{hr}$ pad test is necessary because it is a very useful way to quantify incontinence, superior than Pad per day usage, which is a unreliable measure of incontinence only measuring $38 \%$ of the variation of urinary incontinence volume than $1 \mathrm{hr}$ pad test which is not so sensitive in the detection of slight leakages.

In the study of Lin et al., (2011) stated that in the first hypothesis, the amount of urine leakage would decrease with the passage of time in all participants. The first part of hypothesis, 'urine leakage will decrease', was supported by the results of the mixed model ANOVA that revealed that the main effect of time on the pad test result was significant. The results indicate that urine leakage decreased over time across both groups (measured within subjects). Further post hoc tests revealed a significant difference between the second and third months.

The amount of urine leakage decreased significantly in all patients after the catheter was removed, regardless of the exercise intervention.

The effect suggests that the time is a powerful contributing factor for urine leakage after RP. Moore et al., (2008) found similar continence rates in PFMT and non-PFMT groups for 8 to 52 weeks after treatment. These results are consistent with measurements of urinary leakage over longer follow-up intervals, which indicate that there is a decrease in urine leakage over time as healing take place [13].

The second hypothesis states that males who were included in the pelvic floor exercises group would have greater continence compared to males in the non-exercise group. In this study, a statistically significant main effect of group was found 0.01 . A review of literature indicates inconclusive evidence that PFMT is an effective treatment strategy [14] and well-known treatment strategy for decreasing incontinence episodes after RP suggested that early, non-invasive PFMT has a significant positive impact on the early recovery of urinary incontinence after RP.

Pages et al., (2001) found that patients who participated in pelvic floor therapy had stronger muscle contractions and a more rapid reduction of leakage episodes than patients in the non-exercise group. These results are consistent with those of Filocamo et al., (2005), who found that, after PFMT, the majority of patients $(94.6 \%)$ achieved continence by 6 months post-surgery.

Some studies have also demonstrated that pelvic floor exercises can increase the strength of pelvic floor muscles, allowing these muscles to function as the primary urethral closure mechanism. This improved awareness and muscle strengthening should lead to prophylactic contraction as an automated motor reflex during stress event.

- This article was done 15/4/2019, Cairo University.

\section{Conclusion:}

The current level of evidence to support the effect of pelvic floor exercises on post-prostatectomy urinary incontinence is not sufficient but it may be used to improve the contraction of pelvic floor muscles and quality of life. According to this review, it requires enough support to use the pelvic floor exercises on post-prostatectomy urinary incontinence. There are few conclusions that can be drawn from the existing evidence as follow: (1) It appears to be some evidence favoring intensive and prolonged pelvic floor exercises in improving the quality of life and times of voiding. (2) There is some evidence to indicate that pelvic floor exercises are preferable to improve the urinary incontinence after radical prostatectomy.

\section{References}

1- GAMBRILLE: Evidence-based practice: Implications for knowledge development and use in social work. In A. Rosen and E. Proctor (Eds.), Developing practice guidelines for social work intervention (pp. 37-58). New York: Columbia University Press, 2003. 
2- GILGUN J.: The four cornerstones of qualitative research. Qualitative Health Research, 16 (3): 436-43, 2005.

3- GARG A.X., HACKAM D. and TONELLI M.: Systematic Review and Meta Analysis: When One Study Is Just Not Enough. Clin. J. AM. Soc. Nephrol., 3: 253-60, 2008.

4- ATTIA A. and ABDEL-RAOUF E.: "Essential of EvidenceBased Medicine". 1 st Ed., Higher Education Enhancement Project" Fund., Cairo, pp. 5-6, 2007.

5- COTRELL R.R. and MCKENZIE J.F.: Health Promotion and Education Research Methods using the five-chapter Thesis/Dissertation Model, 2005.

6- LITWIN S., HAYS D., FINK A., et al.: Quality of Life Outcomes In Men Treated For Localized Prostate Cancer. Journal of Urology. Vol (152): 129-35, 1995.

7- BO K.: Urinary Incontinence, Pelvic Floor Dysfunction, Exercise and Sport. Sports Medicine Journal, Vol. (34): 451-64, 2004.

8- WALSH P.C.: Radical Prostatectomy For Localized Prostate Cancer Provides Durable Cancer Control With Excellent Quality of Life: A Structured Depate. Journal of Urology, Vol. (163): 1802-7, 2000.

9- MAHER C.G., SHERRINGTON C., HERBERT R.D.,
MOSELEY A.M. and ELKINS M.: Reliability of the PEDro scale for rating of randomized controlled trials. Phys. Ther., 83: 713-21, 2003.

10- MOSELEY A.M., HERBERT R.D., SHERRINGTON C. and MAHER C.G.: Evidence for physiotherapy practice: A survey of the physiotherapy Evidence Database (PEDro). Australian Journal of Physiotherapy, 48: 43-9, 2002.

11- JEWELL D.: Evidence-Based Physical Therapy Practice In Guide To Evidence-Based Physical Therapy Practice 1 st Ed., Jones and Bartlett Publishers, USA, 2008.

12- MOORE K.N., GLAZENER C.M. and HUNTER K.F. Pelvic Floor Muscle Training To Improve Urinary Incontinence After Radical Prostatectomy: A Systematic Review of Effectiveness. British Journal of Urinary Incontinence, Vol. (100): 1191-1196.

13- VAN KAMPEN M., De WEERDT W., VAN POPPEL H., et al.: Effect of Pelvic Floor Re-education On Duration and Degree of Incontinence After Radical Prostatectomy: Randomized Controlled Trial. The Lancet, Vol. (355): 98-102.

14- PAREKH A.R., FENG M.I., KIRAGES D., et al.: The Role of Pelvic Floor Exercises on Post-Prostatectomy Incontinence. Journal of Urology, Vol. (170): 130-3.

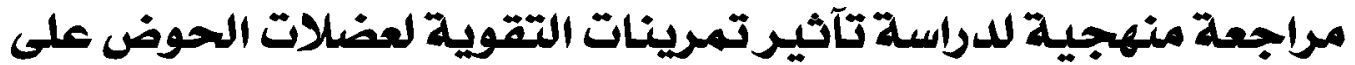

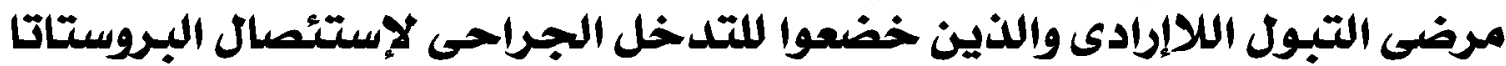

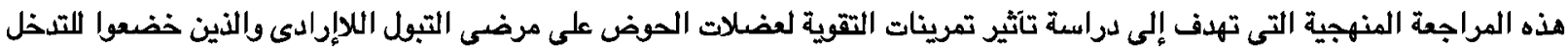

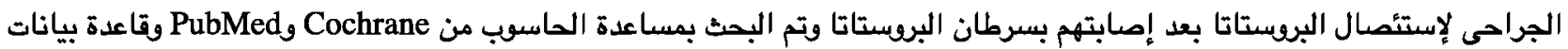

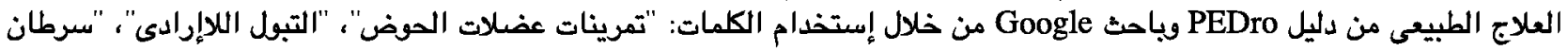

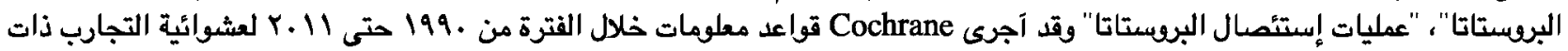

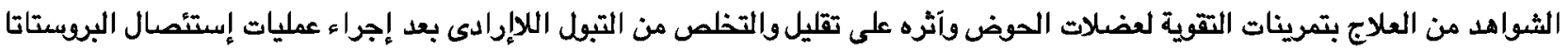
ومن خلال البحث في قاعدة بيانات مصسوبة تشمل الطب والعلات الطية الطبيعى والصحية المصاحبة.

وقد تم البحث من خلال Cochrane في باحث Google لجميع التجارب العشوائية التى تتبع معايير المراجعة (والذين تتراوح آعمارهم ما

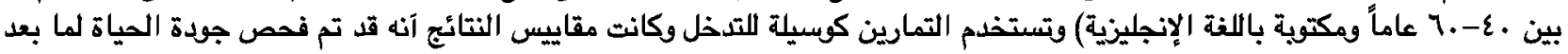

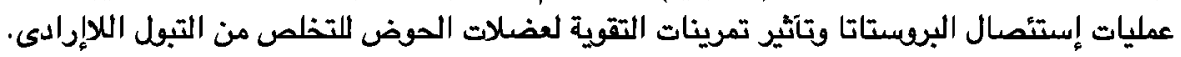

الآهداف: كان الهدف من هذه المراجعة المنهجية دراسة تآثير تمرينات التقوية لعضلات الصوض التخلص من التبول التهات اللإرادى بعد إجراء

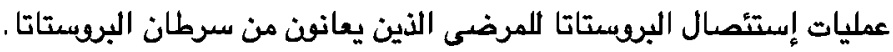

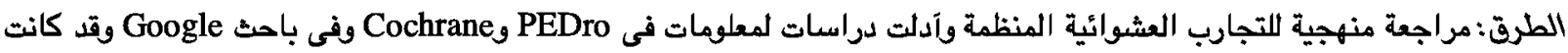

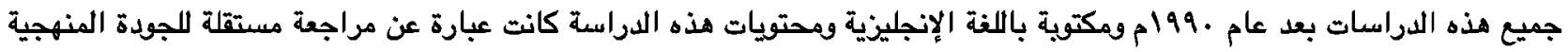
وآخرون) وتعيين مستوى الآدلة (مركز الطب المبنى على البراهين). Van Todler)

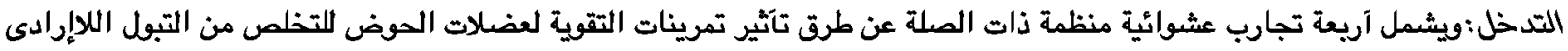

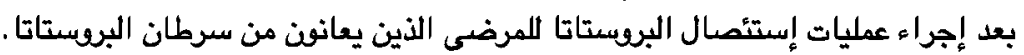

النتائج:تم إختيار آريع دراسات مدرجة فى تحليل"META ANALYSIS' للنتائج الأولية للتبول اللإرادى وجودة الصياة.

الخلاصة" هناك آدلة قوية تدعم تآتير تمرينات التقوية لعضلات الحوض اللتخلص من التبول اللاإرادى بعد إجراء عمليات إستئصسال البروستاتا

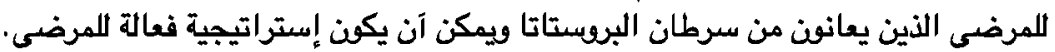

